\title{
Modulation of insulin action
}

\author{
L. Pirola · A. M. Johnston • E. Van Obberghen \\ INSERM Unit 145, Faculty of Medicine, Nice, France
}

\begin{abstract}
Insulin is a key hormone regulating the control of metabolism and the maintenance of normoglycaemia and normolipidaemia. Insulin acts by binding to its cell surface receptor, thus activating the receptor's intrinsic tyrosine kinase activity, resulting in receptor autophosphorylation and phosphorylation of several substrates. Tyrosine phosphorylated residues on the receptor itself and on subsequently bound receptor substrates provide docking sites for downstream signalling molecules, including adapters, protein serine/threonine kinases, phosphoinositide kinases and exchange factors. Collectively, those molecules orchestrate the numerous insulin-mediated physiological responses.

understand the molecular mechanisms that underlie insulin action at the peripheral level, deregulation of which ultimately leads to hyperglycaemia and Type 2 diabetes.

We review how circulating factors such as insulin itself, TNF- $\alpha$, interleukins, fatty acids and glycation products influence insulin action through insulin signalling molecules themselves or through other pathways ultimately impinging on the insulin-signalling pathway. Understanding how the mechanism by which molecular insulin action is modulated by these factors will potentially provide new targets for pharmacological agents, to enable the control of altered glucose and lipid metabolism and diabetes. [Diabetologia (2004) 47:170-184]
\end{abstract}

A clear picture is emerging of the way in which insulin elicits several intracellular signalling pathways to mediate its physiologic functions. A further challenge, being pursued by several laboratories, is to

Keywords Insulin signalling - Insulin resistance · IRS proteins - SOCS proteins · Hyperglycaemia · Hyperinsulinaemia $\cdot$ Serine/threonine phosphorylation

Received: 6 August 2003 / Revised: 4 December 2003 Published online: 13 January 2004

C Springer-Verlag 2004

E. Van Obberghen ( $)$

INSERM Unit 145, Faculty of Medicine, Ave de Valembrose, 06107 Nice Cedex 2, France

E-mail: vanobbeg@unice.fr

Abbreviations: AMPK, Adenosine 5'-monophosphate-activated protein kinase $\cdot$ Erk1/2, extracellular regulated kinase 1 and 2 . GSK-3, glycogen synthase kinase $3 \cdot$ IKK, inhibitor kappa B

kinase $\cdot$ IR, insulin receptor $\cdot$ JAKs, janus kinases $\cdot$ JNK, jun amino terminal kinase $\cdot$ MAPK, mitogen activated protein kinase $\cdot \mathrm{PI} 3 \mathrm{~K}$, phosphoinositide 3-kinase $\cdot \mathrm{PKB}$, protein kinase $\mathrm{B}$. $\mathrm{PKC}$, protein kinase $\mathrm{C} \cdot \mathrm{S} / \mathrm{T}$, serine/threonine $\cdot \mathrm{SOCS}$, suppressor of cytokine signalling $\cdot$ TOR, target of rapamycin

\section{Introduction}

Studies from numerous laboratories in the past 20 years have elucidated the principal features of insulin action at the molecular level [1]. Binding of insulin to its heterotetrameric receptor activates its intracellular tyrosine kinase activity. The cytoplasmic kinase domains of the activated receptor transphosphorylates tyrosines $1158 / 62 / 63$ in the catalytic loop of the kinase domain and subsequently C-terminal tyrosines 1328/34 and the juxtamembrane region tyrosine 972 . Tyrosine 972 is the major docking site for downstream interacting proteins [2]. Insulin receptor interacting proteins (including IRS-1/4, GAB and the recently identified IRS5/DOK4 and IRS6/DOK5 [3]) are in turn phosphorylated on tyrosines providing docking 


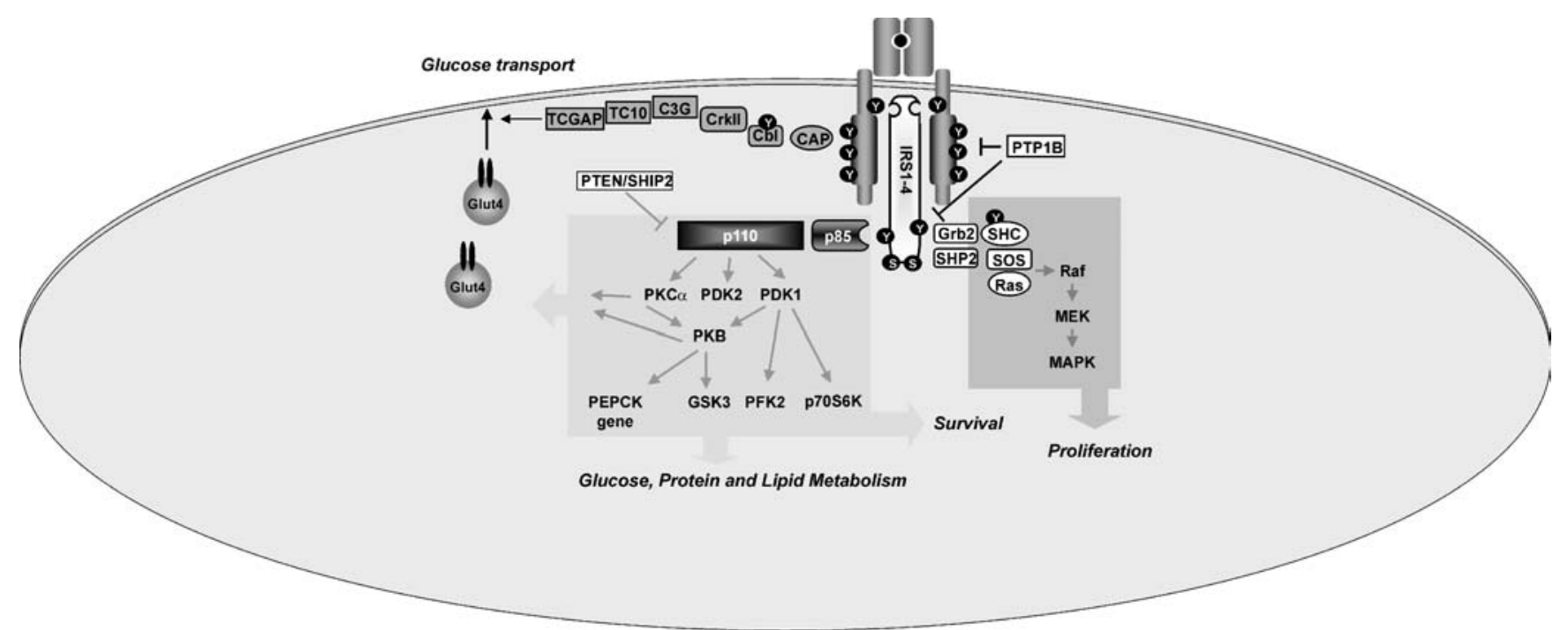

Fig. 1. Principal components of the insulin signalling pathway. Activation of the insulin receptor by its ligand induces autophosphorylation of the receptor, creating docking sites for downstream interacting proteins, such as IRS1 and IRS2. These are themselves phosphorylated and provide further docking sites for $\mathrm{SH} 2$ domain-containing proteins. These events result in the activation of three major pathways, the $\mathrm{PI} 3 \mathrm{~K}, \mathrm{CAP} / \mathrm{Cbl} / \mathrm{Tc} 10$ and the ERK pathway, allowing the transmission of the signals that result ultimately in the diverse biological effects of insulin

sites for SH2 domain containing proteins [4]. The three major pathways emanating from the activated IRS are the PI3K, the CAP/Cbl/Tc10 and the MAPK pathway [5], with the two former pathways mainly involved in the positive control of insulin action (Fig. 1). Insulin has also been shown to promote the activation of $\mathrm{NF} \kappa \mathrm{B}$ by regulating its inhibitor $\mathrm{I} \kappa \mathrm{B}$, via a PI3K-dependent pathway $[6,7]$.

Type I PI3Ks are heterodimeric cytosolic proteins composed of a 50-85 $\mathrm{M}_{\mathrm{r}}$ adapter subunit and a $110 \mathrm{M}_{\mathrm{r}}$ catalytic subunit. PI3Ks are translocated at the plasma membrane by the interaction of the adapter's SH2 domains with tyrosine phosphorylated YxxM motifs on IRS proteins. This interaction positions PI3K in close contact with its substrate-PtdIns $(4,5) P_{2}$ - which is then phosphorylated on the $3^{\prime}$ position of the inositol ring yielding the second messenger $\operatorname{Ptd} \operatorname{Ins}(3,4,5) P_{3}$. PtdIns $(3,4,5) P_{3}$ recruits the $\mathrm{PH}$ domain-containing protein serine kinases PDK-1, PKB and atypical PKCs $\zeta / \lambda$ at the plasma membrane. Membrane-located PDK1 is simultaneously activated by $\operatorname{PtdIns}(3,4,5) P_{3}$ and, by phosphorylating its effectors PKB and PKCs, it relays their full activation $[8,9]$. The activation of this pathway mediates several insulin-induced responses, including GLUT4 translocation at the plasma membrane [10], glycogen synthesis-via PKB mediated inhibitory phosphorylation of GSK-3, a kinase that negatively regulates glycogen synthase-[11], lipogenesis via up-regulation of the expression of the fatty acid synthase gene [12], as well as a more general control of gene expression patterns [13] (Fig. 1).

The necessity of the PI3K pathway for insulininduced GLUT4 translocation and glucose uptake has been shown by the use of pharmacological agents and dominant negative/constitutively active PI3K mutants. However, recent evidence indicates that a parallel pathway acts in concert with the PI3K pathway to fully induce glucose uptake. This pathway is initiated by recruiting the protooncogene $\mathrm{Cbl}$ to the activated insulin receptor via the adapter protein CAP. After tyrosine phosphorylation of $\mathrm{Cbl}$, the CAP-Cbl complex localises to lipid rafts by interacting with the caveolar protein flotillin, thereby forming a ternary complex [14]. Here, Cbl acts by recruiting the guanosine exchange factor $\mathrm{C} 3 \mathrm{G}$ which specifically activates the small GTP binding protein Tc10 [15] and ultimately the Tc10 downstream effector TCGAP [16] (Fig. 1).

The MAPK pathway is also activated by insulin, via both SHC association with the insulin receptor and Grb2 association with both the insulin receptor and IRS molecules. The classic Erk1/2 MAPKs do not play a major role in mediating insulin's metabolic responses, but increased basal MAPK activity seems to contribute to the development of insulin resistance. On the contrary, the p38 MAPK has been proposed as a positive regulator of insulin action because of its capability to increase, in an as yet unknown manner, the uptake of glucose by the plasma membrane-localised GLUT4 transporter [17].

Type 2 diabetes results from a complex interplay between genetic and environmental conditions. At the onset of the disease, the major classic peripheral insulin-responsive tissues, muscle and adipose tissue, display a diminished response to insulin resulting in decreased disposal of excess circulating glucose and fatty acids. Concomitantly, due to reduced insulin action on the liver, hepatic gluconeogenesis increases, further exacerbating hyperglycaemia. In the initial stages of the disease, the pancreatic beta cell compensates by 
secreting an increased amount of insulin. However, during this compensatory hyperinsulinaemic phase existing before overt diabetes develops, progressive beta-cell dysfunction is also observed [18] emphasising the fact that Type 2 diabetes is dependent on insults occurring both at peripheral as well as the betacell level [19]. Thus, when insulin secretory reserves cannot compensate for the defects in peripheral insulin action, overt diabetes results. Evidence obtained from knockout studies in mice indicates that insulin resistance at the level of the beta cell could also be an initial causative factor in diabetes development [19]. Also, it has been shown in human islets that chronic hyperglycaemia, by affecting both insulin receptor gene expression and signalling, impairs insulin secretion [20]. The dysfunctions occurring at the beta-cell level during the progression towards the disease have been reviewed [21, 22]. In addition to these events, the intracellular insulin-signalling machinery in peripheral tissues is deregulated, as a result of a combination of several factors. We review the recent progress towards understanding the modulation of the insulin signalling cascade by circulating factors as well as the understanding of how deregulation of these interactions might contribute to the development of Type 2 diabetes.

\section{Insulin receptor down-regulation}

Insulin resistance is characterised by a diminished responsiveness to the action of insulin at its multiple target organs. The insulin receptor itself is therefore a primary candidate molecule, the down-regulation of which might contribute to the decreased hormone action. Cases of insulin resistance or diabetes have been linked to mutations of the insulin receptor gene [23]. Besides these rare genetically determined cases, early studies showed that the IR tyrosine kinase activity was reduced in insulin-resistant obese mice [24] and in Type 2 diabetic patients [25] independent of insulin receptor genetic variants. This functional down-regulation seemed to depend, in part, on diminished receptor content at the cell surface consequential to increased degradation of the insulin receptor [26, 27]. However, the decreased IR content at the cell surface is not sufficient to account for the loss in IR activity. Thus, a S/T phosphorylation on the cytoplasmic side of the receptor by several PKC isoforms has been proposed as an additional factor contributing to the downregulation of the IR kinase activity. A thorough mutagenesis study of the intracellular part of the IR $\beta$-subunit showed that the serine residues 1189/90/94 located C-terminally to the kinase domain, although not affecting IR autophosphorylation, are required to achieve phosphorylation of the substrates IRS-1, IRS-2 and SHC [28]. A second possible mechanism leading to decreased insulin action in obese subjects and patients with chronic primary hyperinsulinaemia might involve the increased abundance of insulin/insulin-like growth factor-I hybrids in insulin target tissues, a consequence of hyperinsulinaemia-induced IR down-regulation and/ or IGF-1R up-regulation [29, 30].

Restoring IR responsiveness to its natural ligand or mimicking insulin by using pharmacological agents has been a route hotly pursued in pharmaceutical research and has resulted in the discovery of a small insulin-mimicking molecule endowed with antidiabetic activity which, in mice, activates the IR kinase activity [31].

Modulation of the activity and expression of IRS molecules

IRS molecules become readily tyrosine phosphorylated by the activated insulin receptor. To investigate whether a defective activity of the insulin receptor could influence the responsiveness of downstream IRS molecules, the tyrosine phosphorylation state and protein amount of IRS-1 in hyperinsulinaemic $o b / o b$ mice were evaluated, showing that both were reduced in liver and skeletal muscle [32]. Whereas decreased tyrosine phosphorylation might be explained by the defective receptor's activity, novel mechanism(s) had to be invoked to explain the decrease in IRS-1 protein content.

Treatment of isolated soleus muscle and 3T3-L1 adipocytes with okadaic acid, a general inhibitor of serine/threonine phosphatases, diminished IRS protein signalling capability, indicating that $\mathrm{S} / \mathrm{T}$ phosphorylation of IRS might play an inhibitory role [33]. This hypothesis was biochemically confirmed in a IR-expressing $\mathrm{CHO}$ cell system, in which over-expression of the phospholipid- and calcium-activated protein kinase $\mathrm{C}$ had an inhibitory effect on insulin action [34]. Furthermore, an increased serine kinase activity directed towards IRS-1 has been reported in liver and muscles of obese JCR:LA-cp rats [35].

In addition to the IRS-1 down-regulation by serine/threonine phosphorylation mechanisms, a decreased content of IRS proteins has been found in insulin-resistant states in animals, humans and cultured cells as a consequence of hyperinsulinaemia or TNF- $\alpha$ treatment. This decrease is not dependent on defective transcription of the IRS-1 mRNA nor on impaired protein synthesis, rather it is reversed by lactacystin treatment, indicating that hyperinsulinaemia-induced IRS-1 degradation occurs through the proteasome pathway [36]. Thus, the two seemingly separate events of $\mathrm{S} / \mathrm{T}$ phosphorylation and degradation are consequential, as PI3K-mTOR mediated S/T phosphorylation on IRS-1 appears to be necessary to drive IRS-1 to proteasomal degradation [37].

Another less intensively investigated mechanism, which could modulate the signalling potential of 
S/T phosphorylated IRS is interaction with 14-3-3 proteins. The 14-3-3 proteins are widely expressed 28-33- $\mathrm{M}_{\mathrm{r}}$ acidic proteins which spontaneously assemble into dimers. Several 14-3-3 isoforms have been identified to function in several biological processes by binding in a sequence-specific manner to phosphoserine-containing motifs of various signalling proteins, including Raf, Bcr and Foxo transcription factors [38]. Using the two hybrid system and in vitro assays for protein interaction, a study showed the interaction between the $\varepsilon$ isoform of 14-3-3 and IRS-1 [39]. Similarly, by screening a heart cDNA library with ${ }^{32}$ P-labelled IRS-1 and a co-immunoprecitation approach, the $\beta, \varepsilon$ and $\zeta 14-3-3$ isoforms were shown to interact with IRS proteins and work as negative regulators of insulin-induced PI3K activity in 3T3-L1 adipocytes [40, 41]. Then how do the 14-3-3 proteins contribute to the desensitisation of insulin action? Rather than a step leading to proteasomal degradation, a study suggests that 14-3-3, by binding to IRS-1, displaces the IRS-1-PI3K complex from the plasma membrane to the cytosol, thus terminating the PtdIns $(3,4,5) P_{3}$-producing activity of PI3K and eventually leading to decreased downstream signalling [42].

\section{Protein kinases acting upon IRS-1}

PI3K-dependent protein kinases. Upon insulin stimulation, class IA PI3K readily associates with IRS molecules at the plasma membrane and catalyses the formation of PtdIns $(3,4,5) P_{3}$. Class IA PI3Ks are dual-specificity kinases endowed with a protein kinase activity, initially shown towards the serine 608 residue of the p85 $\alpha$ regulatory subunit [43]. In the search for other putative substrates, a study showed that PI3K also phosphorylates IRS-1 in vitro, a wortmannin-reversible process [44]. Nevertheless, it is not clear whether PI3K phosphorylates IRS proteins in vivo and, if so, the possible physiological relevance of this event is still unkown. Towards this end, a study induced cellular insulin resistant state in adipocytes by expressing a constitutively active version of the p110 $\alpha$ PI3K catalytic subunit [45]. However, PI3K inhibition-directed blockade of IRS-1 S/T phosphorylation and amelioration of insulin action also occurs via a number of PI3K-downstream kinases implicated in the phosphorylation and negative regulation of IRS-1, including GSK3, mTOR, and the atypical PKC $\zeta[46$, $47,48,49]$. It has yet to be precisely defined which $\mathrm{S} / \mathrm{T}$ residues are targeted by each kinase and the quantitative contribution of each kinase towards the determination of the overall IRS-1 S/T phosphorylation state. A better understanding of the action of each kinase might permit the pharmacological alteration of the S/T phosphorylation status of IRS-1, thus reversing the associated insulin-resistant state [50].
MAP kinases. Neither of the three major MAPK signalling cascades-namely Erk1/2, p38 and jun amino terminal kinase (JNK) - although activated by insulin, promote insulin-mediated metabolic responses. Rather, they seem to exert feedback regulatory functions. Early observations indicated that, after activation by TNF- $\alpha$, a cytokine known to induce insulin resistance, JNK1 induces phosphorylation of the IRS-1 residue S307 (corresponding to human S312) [51]. S307 is located in the IRS-1 PTB domain, and its phosphorylation is thought to hinder the PTB binding to the activated receptor [52].

In addition to these biochemical studies linking JNK-mediated S307 phosphorylation on IRS-1 to insulin resistance, more physiological evidence has been provided by a JNK-1 KO mouse model that showed ameliorated insulin sensitivity associated with decreased phosphorylation at the JNK-target residue [53]. However, other pathways converge on S307 phosphorylation. Notably, insulin/IGF-1 also promotes phosphorylation at the inhibitory S307 via a PI3K-dependent pathway leading to feedback inhibition of insulin action $[54,55]$. A report using PDK1deficient cells and a pharmacological approach defined a PI3K-PDK-mTOR pathway leading to human S312 phosphorylation and development of cellular insulin resistance, which was reversed in cells expressing a S312A IRS1 mutant [56].

As discussed above, several lines of evidence place S307 as a central phosphorylation target that allows the negative modulation of IRS-1. However, IRS-1 possesses a number of other potential S/T phosphorylation sites, thus action on these sitesespecially on S/T placed close to SH2-domain interacting sequences-might just as well interfere with the action of IRS. Accordingly, a report shows that in primary cultures derived from skeletal muscle of Type 2 diabetic patients, the basal phosphorylation of S636 (S632 in mouse)-a residue in a MAPK consensus sequence-is twofold higher than controls and is decreased by pharmacological inhibition of MAPK [57]. The contribution of Erk1/2 MAPKs to the modulation of the IRS-1 function has also been observed in human embryonic kidney cells treated with an activator of protein kinase $\mathrm{C}$, phorbol 12-myristate 13-acetate [58]. Therefore, increased activity of the Erk1/2 MAPKs could contribute to insulin resistance. Confirmative data have been obtained from TNF- $\alpha$-treated adipocytes, in which the TNF- $\alpha$ induced insulin resistance was reversed by inhibiting Erk1/2 [59] and from studies on muscle biopsies from obese and diabetic patients in which down-regulation of the PI3K, but not MAPK, pathway was observed [60].

The contribution of p38 to the induction of insulinresistance has been studied by adenoviral-mediated overexpression of the upstream kinase MKK6 in 3T3L1 adipocytes. Although increased S/T phosphoryla- 


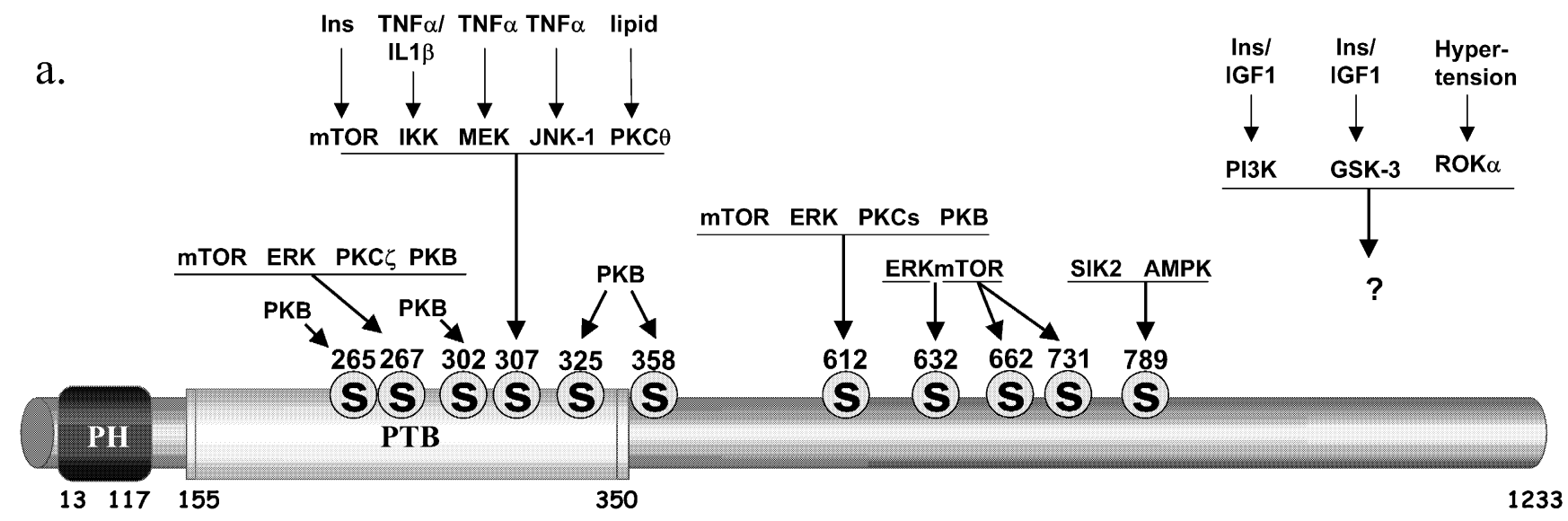

b.

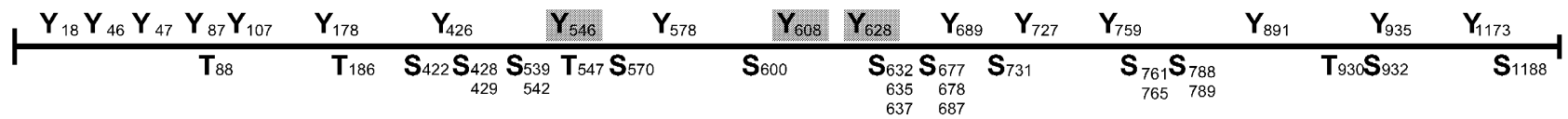

Fig. 2. (a) Schematic of serine phosphorylated residues of mouse IRS1. Shown are the serine residues implicated in the regulation of insulin signalling and the factors that have been shown to induce their phosphorylation. Numbering denotes residue position in mouse IRS1, although some of these sites were first shown in the rat or human homologues. For a description of the various phosphorylation events and their physiological context refer to the text. (b) Schematic of tyrosine residues conserved between IRS1 and IRS2 and the conserved serine and threonine residues found in their vicinity. Numbering denotes residue position according to the sequence of mouse IRS1. Highlighted are tyrosines contained within SH2 consensus motifs conserved between IRS1 and IRS2

tion was not formally demonstrated, activation of p38 moderately inhibited the expression of IRS-1/2 as well as associated PI3K activity, without significantly affecting IR expression and activity [61]. Moreover, in adipocytes of Type 2 diabetic patients, inhibition of p38 reversed the insulin-induced decrease of GLUT4 protein expression but had no effect on the insulinstimulated decrease of IRS-1 [62]. Thus, p38, in contrast to Erk1/2 and JNK, does not appear to negatively regulate insulin action to a major extent. On the contrary, p38 activation-although not impinging in the insulin signalling cascade-directly increases the glucose transport capability of the plasma membrane-located GLUT4 transporter [63].

AMPK and other protein kinases. AMPK is a central metabolic switch that, by phosphorylating key target proteins controlling metabolic pathways, increases skeletal muscle fatty-acid oxidation and represses triglyceride synthesis and lipogenesis. In addition, AMPK mediates the stimulation of glucose uptake in- duced by muscle contraction by a PI3K-independent mechanism. An increased recruitment of the AMPK signalling system could thus correct insulin resistance and Type 2 diabetes resulting from defects in the insulin signalling cascade [64]. Although chiefly acting on a parallel pathway, another report also provides evidence for an interaction between AMPK and the insulin signalling cascade at the level of IRS-1. Murine IRS-1 was phosphorylated by AMPK on S789 both in vitro and in $\mathrm{C}_{2} \mathrm{C}_{12}$ myotubes incubated with the AMPK activator AICAR. This phosphorylation correlated with increased IRS-1-associated PI3K activity after insulin stimulation [65]. Whether AMPK also phosphorylates IRS-2, which also has a serine residue at position 819 that aligns with IRS-1 S789 (Fig. 2b), remains to be determined. More recently, the novel adipocyte-specific AMPK-related protein kinase SIK2 (salt-inducible kinase) has been shown to phosphorylates mouse S789 of IRS-1 (Human S794), thus impairing its action. Of note, both the expression and the catalytic activity of SIK2 is increased in white adipose tissue of $d b / d b$ mice, providing in vivo evidence that SIK2 might negatively modulate insulin action [66].

Further investigation of the roles of AMPK and SIK2 is needed to define whether phosphorylation on the same IRS-1 serine residue might have positive or negative consequences depending on the kinase performing the reaction, or whether the differences seen between AMPK and SIK2 are due to the different cell types studied.

Insulin resistance has circumstantially been associated with activation of the inhibitor kappa B kinase (IKK) based on the following experimental evidence: (i) treatment of obese rodent models with salicylate (an IKK inhibitor when administered at high doses) 


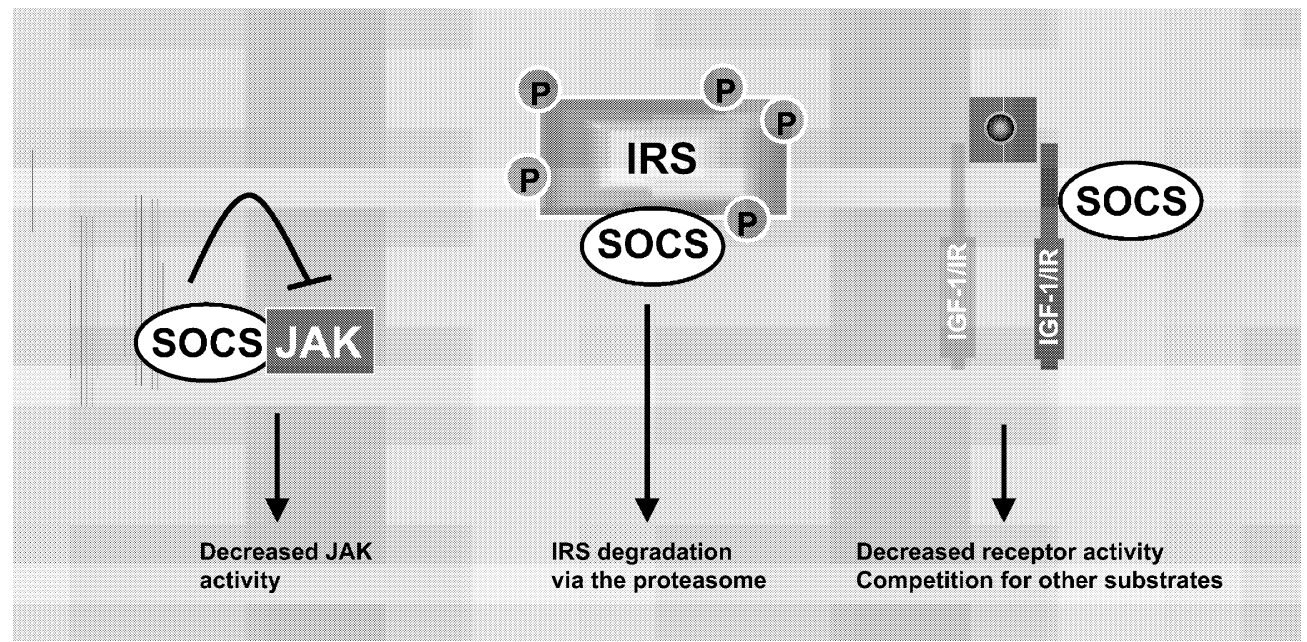

Fig. 3. Modulation by SOCS of the signalling potential of IRS molecules. SOCS modulates IRS signalling potential via at least three mechanisms: via competition for receptor binding sites, inhibition of JAK activity and induction of proteosomal degradation of IRS

sensitised insulin signalling and (ii) genetically obese mice and high-fat fed mice bearing an heterozygous deletion in the gene for the IKK- $\beta$ subunit were protected against the development of insulin resistance [67]. To further evaluate the involvement of IKK in conferring insulin resistance, insulin signalling was measured in rats subjected to hyperinsulinaemic-euglycaemic clamps after lipid infusion following a pretreatment with high doses of salicylate. Lipid infusion decreased insulin action, and salicylate pre-treatment prevented these lipid-induced effects. Moreover, the decreased insulin action in the same experimental setup was not observed in mice lacking IKK- $\beta$ [68]. Mechanistically, IKK targets S307 as assessed by decreased S307 phosphorylation in cells derived from IKK knockout mice or in aspirin-treated cells [69]. However, aspirin seems to exert an additional protective effect by inhibiting the action of other TNF- $\alpha$-activated kinases, including PKB and mTOR [70]. The above experimental evidence suggests that inhibition of the IKK complex by pharmacological means might be efficacious to reverse the conditions of insulin resistance [71]. However, although salicylate treatment and investigation of IKK- $\beta$ heterozygous mice clearly point to a role of IKK- $\beta$ in insulin resistance, direct experimental evidence showing increased IKK activity in insulin resistance and obesity is still missing.

In a two-hybrid study using the PH-PTB domains of IRS-1, Rho kinase $\alpha(\mathrm{ROK} \alpha)$ was identified as a potential IRS-1 binding protein [72]. Further studies showed that hypertension (in spontaneously hypertensive rats), or overexpression of active RhoA(V14), upregulates $\mathrm{ROK} \alpha$ activity, leading to increased $\mathrm{ROK} \alpha$ IRS-1 association, increased IRS-1 serine phosphorylation and subsequent inhibition of insulin signalling.
These results demonstrate the existence of negative crosstalk between $\mathrm{Rho} / \mathrm{ROK} \alpha$ and insulin signalling [73].

Involvement of SOCS proteins in IRS-1/2 modulation

SOCS (suppressor of cytokine signalling) proteins define a family of eight proteins including CIS and SOCS-1 to 7 [74]. CIS, the first member of the SOCS family to be identified, was discovered as an immediate-early gene induced by cytokine treatment which bound activated IL-3 and erythropoietin receptors [75]. More compelling evidence defining SOCS proteins as negative regulators of cytokine signalling came subsequently with the identification of three genes, SOCS-1 to 3, capable of inhibiting the IL-6induced differentiation of M1 cells [76].

Whereas SOCS proteins possess unrelated amino terminal domains of variable length, they share, as similar functional components, a central $\mathrm{SH} 2$ domain and a carboxy-terminal "SOCS box". Mechanistically, SOCS proteins act at three different levels to perform their inhibitory function: (i) via their $\mathrm{SH} 2$ domain they bind and inactivate tyrosine-phosphorylated Janus kinases (JAKs); (ii) SOCS SH2 domains compete with other signal transduction proteins, such as STATs and SHP2, for the access to tyrosine phosphorylated receptor binding sites and (iii) more recent observations indicate that the SOCS box functions as an adaptor that facilitates the ubiquitination and subsequent degradation of various signalling proteins [77] (Fig. 3).

Although SOCS proteins were initially shown to function as negative modulators of cytokine action, recent studies suggest that they are also involved in the negative regulation of insulin signalling. Firstly, SOCS-3 is induced by insulin treatment in insulinresponsive 3T3-L1 adipocytes [78] as well as in insulin-responsive tissues [79]. Induction of SOCS-3 by insulin is directed by STAT5B. A STAT5B binding site is present in the SOCS-3 promoter and cells lacking STAT5B are refractory to SOCS-3 induction by 
insulin $[78,80]$. So how do SOCS proteins act to modulate insulin signalling? Besides being induced by insulin, SOCS-3, as well as SOCS-1, -2 and 6, interact both with the phosphorylated IR and the IGF-1 receptor thus reducing their signalling capabilities $[78,81$, 82]. In addition, SOCS-3 acts as a negative regulator by binding to phosphorylated tyrosine 972 of the IR [78], the major IRS-1 binding residue [83]. However, some controversies have emerged over the fact that the IR might be the sole target for the action of SOCS proteins [84], and evidence has been provided, upon ectopic expression of SOCS proteins, for an action also directed towards IRS-1 with all the three mechanisms mentioned above possibly being involved to different extents $[78,85,86]$. Concerning the suppression of insulin signalling via binding to JAKs, although SOCS binds to JAK with high affinity and overexpression of either SOCS-1 or -3 inhibits insulin-induced JAKs activation [85], it is likely to be a secondary mechanism, due to the small contribution of JAK towards the phosphorylation of IRS molecules. Of probably more physiological significance are the mechanisms acting on the competition for crucial phosphorylated tyrosines on the receptor [78] and on the proteasomal targeting of SOCS-associated proteins after formation of a complex with Elongins $\mathrm{B}$ and $\mathrm{C}$ mediated by the carboxy-terminal portion of the SOCS protein. The occurrence of this last mechanism is neatly demonstrated in a study showing that degradation of IRS-1 and 2 is consequential to the binding to SOCS-1 or 3 and is mediated by the latter's "SOCS box" [86].

The above mentioned studies, although providing a framework for understanding the mode of action of SOCS proteins, often involved in vitro experiments and ectopic expression of SOCS protein at supraphysiological amounts. Nevertheless, physiological approaches have subsequently validated those studies. For example, the implication of SOCS-3 in the development of TNF- $\alpha$-mediated insulin resistance has been directly confirmed by the observations that (i) SOCS-3 is induced in adipose tissue of TNF- $\alpha$ injected mice, (ii) SOCS-3 is overexpressed in obese mice and (iii) obese mice lacking the TNF- $\alpha$ receptor have a reduced SOCS-3 content [79]. In keeping with the negative control mediated by SOCS proteins is the observation that ablation of the SOCS-1 gene yields mice which are hypersensitive to the action of insulin [85].

Whereas most studies linking the expression of SOCS proteins to down-regulation of insulin action mainly focussed on SOCS-1 and -3 , recent observations showed that SOCS-6 also plays a similar role, via its binding to IRS-2 and IRS-4 [87] as well as association with the IR [84]. However, since mice deficient in SOCS-6 do not have defects in glucose homeostasis, it is possible that this isoform plays a minor role in conferring decreased insulin responsiveness.
A deeper understanding is clearly needed to understand how each SOCS protein contributes to the deregulation of the insulin signal, given that these molecules provide a molecular link between cytokine action and their negative consequences on insulin signalling as well as play a direct role in desensitisation of insulin action [88].

\section{Modulation of IRS-downstream proteins}

In parallel to the extensive work which has led to an understanding of how insulin action is regulated by modulation of IRS proteins and their interplay with SOCS proteins, evidence also exists linking the impairment of insulin signalling to events downstream of IRS proteins.

Transcription of the adapter subunit $\mathrm{p} 85 \alpha$ of PI3K is positively regulated by insulin. In muscle biopsies from Type 2 diabetic patients it has been observed that, although basal levels of p85 $\alpha$ mRNA after an overnight fast are not significantly different from con-

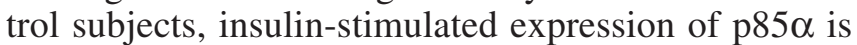
decreased, indicating a role for PI3K expression in the pathogenesis of Type 2 diabetes [89]. A defect of PI3K activity as the first impaired step of the insulin signalling pathway has also been shown upon high-fat feeding in rats, which associated with diminished activities of both PKB and atypical PKCs [90]. However, these observations differ from data generated from a mouse model bearing a heterozygous $\mathrm{p} 85 \alpha$ gene deletion, in which the decreased amount of $\mathrm{p} 85 \alpha$ protein (and thus an higher proportion of $\mathrm{p} 85 \alpha / \mathrm{p} 110$ heterodimeric active PI3K versus the free p85 adapter) leads to a higher sensitivity to insulin [91], which has also been hypothesised to occur owing to an isoform switch from $\mathrm{p} 85 \alpha$ to $\mathrm{p} 50 \alpha$ in the heterozygous animals [92]. These studies highlight the important role of PI3K and its isoforms in glucose homeostasis. Further work will be necessary to clarify whether decreased $\mathrm{p} 85 \alpha$ gene dosage leads to improvement or desensitisation towards insulin action.

Finally, decreased insulin action has also been associated with alterations of glucose transporters. Decreased GLUT4 expression was observed in insulin-resistant and diabetic subjects [93], which is in part compensated by an higher basal GLUT1 content at the plasma membrane [94].

\section{Controversies}

It is now well established that $\mathrm{S} / \mathrm{T}$ phosphorylation mediated by several protein kinases and subsequent proteasomal degradation can modulate the signalling capability of IRS molecules. However, some controversies have yet to be resolved. The first question is whether proteasomal degradation is specific for the 
IRS-1 isoforms or whether this also occurs with the other IRS isoforms. In CHO cells expressing the IR and IRS-1, -2 or chimeras thereof, insulin-induced proteasomal degradation was specific to the IRS-1 isoform, with the $\mathrm{N}$-terminal region including the $\mathrm{PH}$ and PTB domain essential for targeting to the ubiquitin-proteasome degradation pathway [95]. However, contrasting reports show that, in 3T3-L1 fibroblasts and adipocytes, FAO cells and mouse embryo fibroblasts, prolonged insulin treatment induces proteasomal degradation of IRS-2 as well [96]. Similarly, evidence for insulin-induced IRS-1 and 2 degradation has been provided in primary rat adipocytes [97] and L6 muscle cells in which IRS protein degradation occurs via different pathways - a PI3K but mTOR-independent pathway for IRS-1, and a PI3K-mTOR pathway for IRS-2 [98].

Considering the mode of regulation of IRS proteins, it is also controversial whether S/T phosphrylation acts only as a negative regulatory mechanism. In fact, PKB-mediated phosphorylation of mouse IRS-1 on serine residues $265,302,325$ and 358 enhances its action in 293 cells [99] and in vitro a S/T phosphorylation threshold on IRS-1 and 2 must be achieved for full tyrosine phosphorylation by the activated IR to occur [56]. Genetic evidence for a positive role of S/T phosphorylation is provided by the human IRS-1 T608R polymorphism recently identified in a diabetic patient, which impaired metabolic insulin signalling, possibly due to the removal of a potential positive threonine phosphorylation site [100].

While a lot of effort has been directed towards the understanding of the modulatory mechanisms acting upon IRS-1, less is known about the regulation of IRS-2. Given that (i) ablation of IRS-2 leads to overt diabetes [101] and (ii) a number of S/T phosphorylation sites are conserved between IRS-1 and IRS-2, (Fig. 2b) future efforts directed at understanding the molecular events modulating IRS-2 action are foreseeable.

\section{Insulin resistance inducing factors: molecular mechanisms}

\section{Hyperinsulinaemia and hyperglycaemia}

Along with hyperlipidaemia, the most obvious clinical parameters modified in the insulin-resistant state are increased glycaemia and the subsequent compensatory hyperinsulinaemia. Both hyperinsulinaemia and hyperglycaemia per se are factors that exacerbate the insulin-resistant state. Whether hyperinsulinaemia-induced peripheral insulin resistance acts by impairing the tyrosine kinase activity of the IR is still a matter of controversy, with studies showing a decreased receptor activity [25, 102, 103], and others showing a normal IR function, in spite of clear insulin resistance downstream of the receptor and at a metabolic level $[104,105,106]$. In keeping with this second hypothesis is the observation that IRS-1 protein content is reduced in 3T3-L1 adipocytes chronically exposed to insulin [107] as well as in adipocytes from insulinresistant subjects [108] and patients with overt Type 2 diabetes [109]. Likewise, insulin- and IGF-1-induced degradation of IRS-2 has also been proposed to contribute to the insulin-resistant state [96]. Downstream of IRS-1 and -2, other insulin signalling molecules are deregulated by hyperinsulinaemia. PKB activation was reduced in adipose tissue and skeletal muscle from diabetic $d b / d b$ mice [110] and GLUT4 expression is lower in insulin-resistant individuals [93]. Thus, hyperinsulinaemia-induced deterioration of insulin action occurs at several sites along the insulinsignalling pathway.

Hyperglycaemia also has adverse consequences on the efficacy of insulin action. In the liver of the Zucker diabetic rat-during the hypoinsulinaemic and hyperglycaemic phase-tyrosine phosphorylation of IR and IRS-1/2 were significantly enhanced, together with the associated PI3K activity, while activation of PKB was severely suppressed [111]. Similar findings were obtained in a model of neonatally streptozotocintreated Type 1 diabetic rats, in which the resulting hyperglycaemia severely impaired PKB activation and GLUT4 translocation in skeletal muscle, while IRS-1 and -2 associated PI3K activity was enhanced [112]. These observations suggest that hyperglycaemia, either resulting from Type 1 or Type 2 diabetes, does not affect the proximal part of the insulin signalling pathway (IR, IRS and PI3K) but reduces the efficiency of the activation step from PI3K and PKB.

\section{Fatty acids}

High concentrations of circulating fatty acids contribute to the induction of insulin resistance by decreasing insulin-induced PI3K activation. Infusion of a lipid emulsion in rats resulted in a time-dependent intracellular accumulation of acyl-CoA and diacylglycerol which activated $\mathrm{PKC} \theta$, leading to increased PKC $\theta$-mediated IRS-1 phosphorylation on rat S307 [113]. A thorough study addressing the ability of insulin to stimulate PI3K and downstream targets in lipidinfused rats showed fatty acid-mediated impairment of IRS-1/IRS-2 and phosphotyrosine-associated PI3K activity, as well as of the activation state of the kinases $\mathrm{PKB} \alpha, \mathrm{PKC} \lambda / \zeta$ and GSK $-3 \alpha$ and $\beta$, while PKB $\beta$ and p70 ${ }^{\mathrm{S} 6 \mathrm{k}}$ were not impaired [114]. The definition of the deregulated protein kinase cascades in animal or cellculture models might translate into a pharmacological application, as a similar mechanism, notably the fatty acid-induced decrease in IRS-1-associated PI3K activity, has been observed in biopsies from healthy human subjects infused with fatty acids [115]. 
As discussed above, increased fatty acid concentrations inhibit insulin-mediated glucose metabolism by affecting a number of protein kinases. A further molecule with deregulated expression has been found in transgenic mice overexpressing the lipoprotein lipase (LPL) in skeletal muscle. Munc18c is a negative regulator of insulin-induced GLUT4 translocation and was increased in LPL transgenics, implicating it as contributing to fatty acid-induced insulin resistance [116].

Studies in the INS-1 pancreatic beta-cell line indicate that increased concentrations of fatty acids also inhibit the compensatory mass expansion of beta cells that occurs during insulin resistance. This inhibition of beta-cell mitogenesis originates from fatty acidinduced activation of several PKC isoforms and a subsequent decreased activation of PKB by insulin or IGF-1 [117].

Although high concentrations of fatty acids have negative consequences on insulin action, it should be emphasised that unsaturated fatty acids might have, at least a partially beneficial action [118]. A recent study on high-fat diet fed rats indicated that the presence of 3 -polyunsaturated fatty acids in the diet, although unable to prevent the development of hyperinsulinaema, hyperglycaemia and liver insulin resistance, allowed the maintainance of normal insulin sensitivity in muscle [119].

\section{TNF- $\alpha$ and other cytokines}

Interleukin 1 (IL-1), IL-6 and TNF- $\alpha$ are pro-inflammatory cytokines essential for mediating the immune response to pathogens. In addition, they are also predisposing factors towards the development of obesity and insulin resistance [120]. Moreover, subclinical inflammatory reactions dependent on increased circulating levels of IL-1 $\beta$ and IL-6 are associated with an increased risk of developing Type 2 diabetes [121].

Among the various pro-inflammatory cytokines, adipose tissue-produced TNF- $\alpha$ was first recognised as an insulin resistance-inducing agent and its expression is increased in the adipose tissue of several animal models of obesity [122]. TNF- $\alpha$ decreases insulin signalling by impairing the insulin-stimulated tyrosine phosphorylation of IRS molecules, both via phosphorylation of IRS-1 S307 and the induction of SOCS proteins. In addition, new observations of the mechanism of TNF- $\alpha$-induced insulin resistance indicate that the induction of cellular stress by TNF- $\alpha$ leads to activation of ErbB2/ErbB3 and recruitment of PI3K. This ternary complex is able to cross-talk at the level of the insulin pathway by inducing serine phosphorylation on IRS proteins, ultimately leading to insulin resistance [123].

Another pro-inflammatory cytokine implicated in insulin resistance is IL-6, which inhibits insulin sig- nalling in hepatocytes [124]. Similar to TNF- $\alpha$, IL-6induced insulin resistance occurs via the induction of SOCS-3 [125].

Besides being released to regulate inflammatory events, multiple cytokines that contribute to the development of insulin resistance are induced in monocytes after exposure to a hyperglycaemic milieu, these include the monocyte chemoattractant protein 1 (MCP-1), TNF- $\alpha$ and IL-1 $\beta$ [126]. Thus, inflammatory states can be viewed as predisposing factors for the development of insulin resistance [120].

Since increased pro-inflammatory cytokine levels are triggers for inducing insulin resistance, antiinflammatory cytokines such as IL-10 might have the opposite effect. In fact, an epidemiological study showed that a low IL-10 production capacity, leading to a pro-inflammatory response, was associated with Type 2 diabetes [127].

Glycated proteins and advanced glycated end products

Glucose and other reducing sugars slowly react nonenzymatically with free amino groups of both intraand extracellular proteins forming early glycation products (Schiff bases) and intermediate glycation products (Amadori products). These glycated proteins are further degraded to AGE, a heterogeneous class of compounds which includes glyoxal, methylglyoxal, carboxymethyl-lysine and others [128]. Increased AGE have been associated with various diabetic complications, including diabetic retinopathy, neuropathy and nephropathy as well as cataract formation and diabetic atherosclerotic disease. However, it is not yet known whether accumulation of AGE is directly responsible for the above complications or a mere consequence of them. Likewise, although glycated haemoglobin is used as an analytical index to monitor long-term blood glucose control, little is known about the role that glycated proteins can play in the pathophysiology of diabetes.

As glycation is a non-enzymatic reaction, it can occur on any protein. Insulin itself has been shown to be glycated within beta cells, resulting in impaired biological activity [129]. In a recent report, by using a specific radioimmunoassay, it was shown that glycated insulin circulates at higher concentration in Type 2 diabetic patients [130].

Increased circulating amounts of glycated albumin - a major long-lived protein component of serum-and AGE have been associated with the development of diabetic retinopathy $[131,132]$ via induction of vascular endothelial growth factor expression [133] and diabetic nephropathy [134].

Glycated albumin also acts intracellularly by downregulating the metabolic effects of insulin in L6 skeletal muscle cells without affecting the mitogenic action of the hormone. Thus, pre-treatment of L6 cells with 
glycated albumin leads to decreased insulin-induced PI3K, PKB and GSK-3 activation-resulting in impaired glucose uptake and glycogen synthesis-without affecting the insulin-induced activation of the MAPK Erk1/2 and its associated mitogenic action. This differential effect on insulin signalling seems to be mediated by specific PKC $\alpha$-mediated serine phosphorylation of IRS-1 that differentially affects the two major insulin-signalling cascades [135].

\section{Glucosamine}

The glucosamine biosynthetic pathway, although quantitatively utilising a small fraction of glucose, is yet another contributor to the insulin-resistant state. Glucose, once imported into the cell, is converted to fructose-6-phosphate (Fru-6-P). While the majority of Fru-6-P enters the glycolytic pathway, a small fraction $(1-3 \%)$ is used by the hexosamine biosynthetic pathway to produce UDP-N-acetyl-glucosamine, a major substrate for glycosylation reactions [136]. Earlier studies showed that an increased metabolic flux through the hexosamine pathway led to the desensitisation of the glucose transport system in adipocytes [137]. Likewise, several studies showed that chronic exposure to glucosamine-a precursor of the hexosamine pathway-impairs insulin responsiveness, thus contributing to the formation of an insulin-resistant state in cultured human skeletal muscle cells [138], and rat adipocytes [139]. At the molecular level, the insulin resistance induced by the hexosamine pathway correlates with increased glycosylation-and subsequent deregulation - of various proteins involved in insulin action, including IRS-1, which leads to diminished insulin-stimulated phosphorylation of T308 of PKB and S9 of GSK-3 [140]; and the syntaxin 4 binding protein Munc18c, resulting in a reduced insulinstimulated GLUT4 translocation at the plasma membrane [141]. Similarly, increased glycosylation of glycogen synthase contributes to its reduced activation by insulin [142].

Further evidence for the role of the hexosamine pathway in conferring insulin resistance came from two transgenic mouse models overexpressing glutamine:fructose-6-phosphate amidotransferase (GFAT), the pathway's rate-limiting enzyme, in the liver and skeletal muscle. Transgenics expressing GTAF in the liver developed hyperlipidaemia and became obese and insulin resistant [143] and skeletal muscle GTAF overexpression led to decreased GLUT4 translocation [144]. On the contrary, contrasting reports exist as to whether the hexosamine pathway reduces insulin sensitivity upon short-term exposure to glucosamine $[145,146]$.

In addition to its negative action at the peripheral level, activation of the hexosamine pathway also deteriorates beta-cell function. Adenoviral-mediated over- expression of GFAT in isolated rat islets impaired glucose-stimulated insulin secretion and decreased the expression of beta-cell-specific genes including GLUT2, insulin and glucokinase. Treatment of beta cells with an anti-oxidant, however, reversed the effects of overexpressed GFAT, suggesting that the deterioration of beta-cell function occurs via the induction of oxidative stress [147].

\section{Conclusions}

As briefly discussed, it is clear that regulation of insulin signalling takes place at several levels. In addition to the "classic" action of protein phosphatases, which restore the dephosphorylated/inactive state of the IR, IRS proteins and downstream kinases (for reviews see $[148,149])$, more recently described molecular events such as protein $\mathrm{S} / \mathrm{T}$ phosphorylation and degradation mainly acting on IRS proteins, impair insulin action.

Of particular interest is the link between these molecular events and the onset of insulin resistance and diabetes, with deregulated concentrations of circulating factors (cytokines, insulin itself, etc.), metabolites (glucose, glucosamine, fatty acids) or glycated proteins and AGE, which often contribute to the aggravation of the insulin-resistant or diabetic condition by acting via overlapping mechanisms.

The current picture and future improvements in our understanding of the S/T phosphorylation pathways on IRS-1 (and IRS-2) and action of SOCS proteins, will define a number of putative targets, the inhibition of which might relieve the negative effects caused by the insulin-resistant state. If proteins which act by down-regulating insulin action can be identified and made the target of novel bioactive molecules, this could eventually lead to the development of new drugs to be used for the prevention and treatment of the insulin-resistant state, and hence diabetes.

Sources. This review is mainly based on the relevant literature published in the English language from 2000 and available through PubMed. Major prior contributions have been nevertheless cited. Cited papers were identified through PubMed searches for "insulin", "IRS", "SOCS" and "insulin resistance" and through reading of the recent literature.

Acknowledgements. We apologise to all the researchers working in the field of modulation of insulin action whose work, due to space limitations, could not be cited. L. Pirola was supported by FRM (Fondation pour la Recherche Médicale) and by a "Poste Vert" postdoctoral fellowship, A.M. Johnston was supported by an INSERM "Poste Vert" postdoctoral fellowship. Our work discussed in this review was supported by INSERM, Université de Nice-Sophia-Antipolis, la Région PACA, Aventis (Frankfurt, Germany), Lipha-Merck (Lyon, France) and the European Community (grants QLGI-CT-199900674 and QLK3-CT-2000-01038). 


\section{References}

1. Lizcano JM, Alessi DR (2002) The insulin signalling pathway. Curr Biol 12:R236-R238

2. Kido Y, Nakae J, Accili D (2001) Clinical review 125: the insulin receptor and its cellular targets. J Clin Endocrinol Metab 86:972-979

3. Cai D, Dhe-Paganon S, Melendez PA, Lee J, Shoelson SE (2003) Two new substrates in insulin signaling, IRS5/ DOK4 and IRS6/DOK5. J Biol Chem 278:25323-25330

4. White MF (1997) The insulin signalling system and the IRS proteins. Diabetologia 40:S2-S17

5. Saltiel AR, Kahn CR (2001) Insulin signalling and the regulation of glucose and lipid metabolism. Nature 414:799-806

6. Bertrand F, Atfi A, Cadoret A et al. (1998) A role for nuclear factor kappaB in the antiapoptotic function of insulin. J Biol Chem 273:2931-2938

7. Pandey SK, He HJ, Chesley A, Juhaszova M, Crow MT, Bernier M (2002) Wortmannin-sensitive pathway is required for insulin-stimulated phosphorylation of inhibitor kappaBalpha. Endocrinology 143:375-385

8. Vanhaesebroeck B, Alessi DR (2000) The PI3K-PDK1 connection: more than just a road to PKB. Biochem J 346:561-576

9. Brazil DP, Hemmings BA (2001) Ten years of protein kinase B signalling: a hard Akt to follow. Trends Biochem Sci 26:657-664

10. Khan AH, Pessin JE (2002) Insulin regulation of glucose uptake: a complex interplay of intracellular signalling pathways. Diabetologia 45:1475-1483

11. Cross DA, Alessi DR, Cohen P, Andjelkovich M, Hemmings BA (1995) Inhibition of glycogen synthase kinase- 3 by insulin mediated by protein kinase B. Nature 378:785-789

12. Girard J, Perdereau D, Foufelle F, Prip-Buus C, Ferre P (1994) Regulation of lipogenic enzyme gene expression by nutrients and hormones. FASEB J 8:36-42

13. O'Brien RM, Streeper RS, Ayala JE, Stadelmaier BT, Hornbuckle LA (2001) Insulin-regulated gene expression. Biochem Soc Trans 29:552-558

14. Baumann CA, Ribon V, Kanzaki M et al. (2000) CAP defines a second signalling pathway required for insulinstimulated glucose transport. Nature 407:202-207

15. Chiang SH, Baumann CA, Kanzaki M et al. (2001) Insulinstimulated GLUT4 translocation requires the CAP-dependent activation of TC10. Nature 410:944-948

16. Chiang SH, Hwang J, Legendre M, Zhang M, Kimura A, Saltiel AR (2003) TCGAP, a multidomain Rho GTPaseactivating protein involved in insulin-stimulated glucose transport. EMBO J 22:2679-2691

17. Somwar R, Koterski S, Sweeney G et al. (2002) A dominant-negative p38 MAPK mutant and novel selective inhibitors of p38 MAPK reduce insulin-stimulated glucose uptake in 3T3-L1 adipocytes without affecting GLUT4 translocation. J Biol Chem 277:50386-50395

18. Kahn SE (2003) The relative contributions of insulin resistance and beta-cell dysfunction to the pathophysiology of Type 2 diabetes. Diabetologia 46:3-19

19. Kahn CR, Bruning JC, Michael MD, Kulkarni RN (2000) Knockout mice challenge our concepts of glucose homeostasis and the pathogenesis of diabetes mellitus. J Pediatr Endocrinol Metab 13:1377-1384

20. Hribal ML, Perego L, Lovari S et al. (2003) Chronic hyperglycemia impairs insulin secretion by affecting insulin receptor expression, splicing, and signaling in RIN beta cell line and human islets of Langerhans. FASEB J $17: 1340-1342$
21. Sesti G (2002) Apoptosis in the beta cells: cause or consequence of insulin secretion defect in diabetes? Ann Med 34:444-450

22. LeRoith D (2002) Beta-cell dysfunction and insulin resistance in type 2 diabetes: role of metabolic and genetic abnormalities. Am J Med 113:3S-11S

23. Accili D, Cama A, Barbetti F, Kadowaki H, Kadowaki T, Taylor SI (1992) Insulin resistance due to mutations of the insulin receptor gene: an overview. J Endocrinol Invest 15:857-864

24. Le Marchand-Brustel Y, Gremeaux T, Ballotti R, Van Obberghen E (1985) Insulin receptor tyrosine kinase is defective in skeletal muscle of insulin-resistant obese mice. Nature 315:676-679

25. Arner P, Pollare T, Lithell H, Livingston JN (1987) Defective insulin receptor tyrosine kinase in human skeletal muscle in obesity and type 2 (non-insulindependent) diabetes mellitus. Diabetologia 30:437440

26. Harrison LC, Itin A, Kasuga M, Van Obberghen E (1982) The insulin receptor on the human lymphocyte: insulininduced down-regulation of 126,000 and 90,000 glycosylated subunits. Diabetologia 22:233-238

27. Taylor SI, Samuels B, Roth J et al. (1982) Decreased insulin binding in cultured lymphocytes from two patients with extreme insulin resistance. J Clin Endocrinol Metab 54:919-930

28. Bossenmaier B, Strack V, Stoyanov B et al. (2000) Serine residues $1177 / 78 / 82$ of the insulin receptor are required for substrate phosphorylation but not autophosphorylation. Diabetes 49:889-895

29. Federici M, Lauro D, D'Adamo M et al. (1998) Expression of insulin/IGF-I hybrid receptors is increased in skeletal muscle of patients with chronic primary hyperinsulinemia. Diabetes 47:87-92

30. Federici M, Porzio O, Lauro D et al. (1998) Increased abundance of insulin/insulin-like growth factor-I hybrid receptors in skeletal muscle of obese subjects is correlated with in vivo insulin sensitivity. J Clin Endocrinol Metab 83:2911-2915

31. Zhang B, Salituro G, Szalkowski D et al. (1999) Discovery of a small molecule insulin mimetic with antidiabetic activity in mice. Science 284:974-977

32. Saad MJ, Araki E, Miralpeix M, Rothenberg PL, White MF, Kahn CR (1992) Regulation of insulin receptor substrate-1 in liver and muscle of animal models of insulin resistance. J Clin Invest 90:1839-1849

33. Jullien D, Tanti JF, Heydrick SJ et al. (1993) Differential effects of okadaic acid on insulin-stimulated glucose and amino acid uptake and phosphatidylinositol 3-kinase activity. J Biol Chem 268:15246-15251

34. Roth RA, Liu F, Chin JE (1994) Biochemical mechanisms of insulin resistance. Horm Res 41:51-55

35. Qiao LY, Goldberg JL, Russell JC, Sun XJ (1999) Identification of enhanced serine kinase activity in insulin resistance. J Biol Chem 274:10625-10632

36. Sun XJ, Goldberg JL, Qiao LY, Mitchell JJ (1999) Insulininduced insulin receptor substrate- 1 degradation is mediated by the proteasome degradation pathway. Diabetes 48:1359-1364

37. Haruta T, Uno T, Kawahara J et al. (2000) A rapamycinsensitive pathway down-regulates insulin signaling via phosphorylation and proteasomal degradation of insulin receptor substrate-1. Mol Endocrinol 14:783-794

38. Tzivion G, Avruch J (2002) 14-3-3 proteins: active cofactors in cellular regulation by serine/threonine phosphorylation. J Biol Chem 277:3061-3064 
39. Craparo A, Freund R, Gustafson TA (1997) 14-3-3 (epsilon) interacts with the insulin-like growth factor I receptor and insulin receptor substrate I in a phosphoserine-dependent manner. J Biol Chem 272:11663-11669

40. Ogihara T, Isobe T, Ichimura T et al. (1997) 14-3-3 protein binds to insulin receptor substrate-1, one of the binding sites of which is in the phosphotyrosine binding domain. J Biol Chem 272:25267-25274

41. Kosaki A, Yamada K, Suga J, Otaka A, Kuzuya H (1998) 14-3-3beta protein associates with insulin receptor substrate 1 and decreases insulin-stimulated phosphatidylinositol 3'-kinase activity in 3T3L1 adipocytes. J Biol Chem 273:940-944

42. Xiang X, Yuan M, Song Y, Ruderman N, Wen R, Luo Z (2002) 14-3-3 facilitates insulin-stimulated intracellular trafficking of insulin receptor substrate 1. Mol Endocrinol 16:552-562

43. Dhand R, Hiles I, Panayotou G et al. (1994) PI 3-kinase is a dual specificity enzyme: autoregulation by an intrinsic protein-serine kinase activity. EMBO J 13:522-533

44. Lam K, Carpenter CL, Ruderman NB, Friel JC, Kelly KL (1994) The phosphatidylinositol 3-kinase serine kinase phosphorylates IRS-1. Stimulation by insulin and inhibition by Wortmannin. J Biol Chem 269:20648-20652

45. Egawa K, Sharma PM, Nakashima N et al. (1999) Membrane-targeted phosphatidylinositol 3-kinase mimics insulin actions and induces a state of cellular insulin resistance. J Biol Chem 274:14306-14314

46. Eldar-Finkelman H, Krebs EG (1997) Phosphorylation of insulin receptor substrate 1 by glycogen synthase kinase 3 impairs insulin action. Proc Natl Acad Sci USA 94:96609664

47. Ozes ON, Akca H, Mayo LD et al. (2001) A phosphatidylinositol 3-kinase/Akt/mTOR pathway mediates and PTEN antagonizes tumor necrosis factor inhibition of insulin signaling through insulin receptor substrate-1. Proc Natl Acad Sci USA 98:4640-4645

48. Liu YF, Paz K, Herschkovitz A et al. (2001) Insulin stimulates PKCzeta -mediated phosphorylation of insulin receptor substrate-1 (IRS-1). A self-attenuated mechanism to negatively regulate the function of IRS proteins. J Biol Chem 276:14459-14465

49. Ravichandran LV, Esposito DL, Chen J, Quon MJ (2001) Protein kinase C-zeta phosphorylates insulin receptor substrate- 1 and impairs its ability to activate phosphatidylinositol 3-kinase in response to insulin. J Biol Chem 276:3543-3549

50. Sykiotis GP, Papavassiliou AG (2001) Serine phosphorylation of insulin receptor substrate-1: a novel target for the reversal of insulin resistance. Mol Endocrinol 15:18641869

51. Aguirre V, Uchida T, Yenush L, Davis R, White MF (2000) The c-Jun $\mathrm{NH}(2)$-terminal kinase promotes insulin resistance during association with insulin receptor substrate-1 and phosphorylation of Ser(307). J Biol Chem 275:90479054

52. Aguirre V, Werner ED, Giraud J, Lee YH, Shoelson SE, White MF (2002) Phosphorylation of Ser307 in insulin receptor substrate-1 blocks interactions with the insulin receptor and inhibits insulin action. J Biol Chem 277:15311537

53. Hirosumi J, Tuncman G, Chang L et al. (2002) A central role for JNK in obesity and insulin resistance. Nature 420:333-336

54. Rui L, Aguirre V, Kim JK et al. (2001) Insulin/IGF-1 and TNF-alpha stimulate phosphorylation of IRS-1 at inhibitory Ser307 via distinct pathways. J Clin Invest 107:181-189
55. Lee YH, Giraud J, Davis RJ, White MF (2003) c-Jun N-terminal kinase (JNK) mediates feedback inhibition of the insulin signaling cascade. J Biol Chem 278:2896-2902

56. Greene MW, Sakaue H, Wang L, Alessi DR, Roth RA (2003) Modulation of insulin-stimulated degradation of human insulin receptor substrate-1 by serine 312 phosphorylation. J Biol Chem 278:8199-8211

57. Bouzakri K, Roques M, Gual P et al. (2003) Reduced activation of phosphatidylinositol-3 kinase and increased serine 636 phosphorylation of insulin receptor substrate-1 in primary culture of skeletal muscle cells from patients with type 2 diabetes. Diabetes 52:1319-1325

58. De Fea K, Roth RA (1997) Modulation of insulin receptor substrate-1 tyrosine phosphorylation and function by mitogen-activated protein kinase. J Biol Chem 272:31400-31406

59. Engelman JA, Berg AH, Lewis RY, Lisanti MP, Scherer PE (2000) Tumor necrosis factor alpha-mediated insulin resistance, but not dedifferentiation, is abrogated by MEK $1 / 2$ inhibitors in 3T3-L1 adipocytes. Mol Endocrinol 14:15571569

60. Cusi K, Maezono K, Osman A et al. (2000) Insulin resistance differentially affects the PI 3-kinase- and MAP kinase-mediated signaling in human muscle. J Clin Invest 105:311-320

61. Fujishiro M, Gotoh Y, Katagiri H et al. (2003) Three mitogen-activated protein kinases inhibit insulin signaling by different mechanisms in 3T3-L1 adipocytes. Mol Endocrinol 17:487-497

62. Carlson CJ, Koterski S, Sciotti RJ, Poccard GB, Rondinone CM (2003) Enhanced basal activation of mitogen-activated protein kinases in adipocytes from type 2 diabetes: potential role of p38 in the downregulation of GLUT4 expression. Diabetes 52:634-641

63. Huang C, Somwar R, Patel N, Niu W, Torok D, Klip A (2002) Sustained exposure of L6 myotubes to high glucose and insulin decreases insulin-stimulated GLUT4 translocation but upregulates GLUT4 activity. Diabetes 51:20902098

64. Winder WW, Hardie DG (1999) AMP-activated protein kinase, a metabolic master switch: possible roles in type 2 diabetes. Am J Physiol 277:E1-E10

65. Jakobsen SN, Hardie DG, Morrice N, Tornqvist HE (2001) 5'-AMP-activated protein kinase phosphorylates IRS-1 on Ser-789 in mouse $\mathrm{C} 2 \mathrm{C} 12$ myotubes in response to 5-aminoimidazole-4-carboxamide riboside. J Biol Chem 276:46912-46916

66. Horike N, Takemori H, Katoh Y et al. (2003) Adiposespecific expression, phosphorylation of Ser794 in insulin receptor substrate-1, and activation in diabetic animals of salt-inducible kinase-2. J Biol Chem 278:18440-18447

67. Yuan M, Konstantopoulos N, Lee J et al. (2001) Reversal of obesity- and diet-induced insulin resistance with salicylates or targeted disruption of Ikkbeta. Science 293:16731677

68. Kim JK, Kim YJ, Fillmore JJ et al. (2001) Prevention of fat-induced insulin resistance by salicylate. J Clin Invest 108:437-446

69. Gao Z, Hwang D, Bataille F et al. (2002) Serine phosphorylation of insulin receptor substrate 1 by inhibitor kappa B kinase complex. J Biol Chem 277:48115-48121

70. Gao Z, Zuberi A, Quon MJ, Dong Z, Ye J (2003) Aspirin inhibits serine phosphorylation of insulin receptor substrate 1 in tumor necrosis factor-treated cells through targeting multiple serine kinases. J Biol Chem 278:24944-24950

71. Burke JR (2003) Targeting I kappa B kinase for the treatment of inflammatory and other disorders. Curr Opin Drug Discov Devel 6:720-728 
72. Farah S, Agazie Y, Ohan N, Ngsee JK, Liu XJ (1998) A rho-associated protein kinase, ROKalpha, binds insulin receptor substrate-1 and modulates insulin signaling. J Biol Chem 273:4740-4746

73. Begum N, Sandu OA, Ito M, Lohmann SM, Smolenski A (2002) Active Rho kinase (ROK-alpha ) associates with insulin receptor substrate- 1 and inhibits insulin signaling in vascular smooth muscle cells. J Biol Chem 277:6214-6222

74. Alexander WS (2002) Suppressors of cytokine signalling (SOCS) in the immune system. Nat Rev Immunol 2:410-416

75. Yoshimura A, Ohkubo T, Kiguchi T et al. (1995) A novel cytokine-inducible gene CIS encodes an SH2-containing protein that binds to tyrosine-phosphorylated interleukin 3 and erythropoietin receptors. Embo J 14:2816-28126

76. Starr R, Willson TA, Viney EM et al. (1997) A family of cytokine-inducible inhibitors of signalling. Nature 387:917921

77. Kile BT, Schulman BA, Alexander WS, Nicola NA, Martin HM, Hilton DJ (2002) The SOCS box: a tale of destruction and degradation. Trends Biochem Sci 27:235-241

78. Emanuelli B, Peraldi P, Filloux C, Sawka-Verhelle D, Hilton D, Van Obberghen E (2000) SOCS-3 is an insulininduced negative regulator of insulin signaling. J Biol Chem 275:15985-15991

79. Emanuelli B, Peraldi P, Filloux C et al. (2001) SOCS-3 inhibits insulin signaling and is up-regulated in response to tumor necrosis factor-alpha in the adipose tissue of obese mice. J Biol Chem 276:47944-47949

80. Sadowski CL, Choi TS, Le M, Wheeler TT, Wang LH, Sadowski HB (2001) Insulin Induction of SOCS-2 and SOCS-3 mRNA expression in C2C12 Skeletal Muscle Cells Is Mediated by Stat5*. J Biol Chem 276:2070320710

81. Dey BR, Furlanetto RW, Nissley P (2000) Suppressor of cytokine signaling (SOCS)-3 protein interacts with the insulin-like growth factor-I receptor. Biochem Biophys Res Commun 278:38-43

82. Dey BR, Spence SL, Nissley P, Furlanetto RW (1998) Interaction of human suppressor of cytokine signaling (SOCS)-2 with the insulin-like growth factor-I receptor. J Biol Chem 273:24095-24101

83. Kaburagi Y, Momomura K, Yamamoto-Honda R et al. (1993) Site-directed mutagenesis of the juxtamembrane domain of the human insulin receptor. J Biol Chem 268:16610-16622

84. Mooney RA, Senn J, Cameron S et al. (2001) Suppressors of cytokine signaling-1 and -6 associate with and inhibit the insulin receptor. A potential mechanism for cytokinemediated insulin resistance. J Biol Chem 276:25889-25893

85. Kawazoe Y, Naka T, Fujimoto M et al. (2001) Signal transducer and activator of transcription (STAT)-induced STAT inhibitor 1 (SSI-1)/suppressor of cytokine signaling 1 (SOCS1) inhibits insulin signal transduction pathway through modulating insulin receptor substrate 1 (IRS-1) phosphorylation. J Exp Med 193:263-269

86. Rui L, Yuan M, Frantz D, Shoelson S, White MF (2002) SOCS-1 and SOCS-3 block insulin signaling by ubiquitinmediated degradation of IRS1 and IRS2. J Biol Chem 277:42394-42398

87. Krebs DL, Uren RT, Metcalf D et al. (2002) SOCS-6 binds to insulin receptor substrate 4, and mice lacking the SOCS-6 gene exhibit mild growth retardation. Mol Cell Biol 22:4567-4578

88. Krebs DL, Hilton DJ (2003) A new role for SOCS in insulin action. Suppressor of cytokine signaling. Sci STKE 2003(169):PE6
89. Andreelli F, Laville M, Ducluzeau PH et al. (1999) Defective regulation of phosphatidylinositol-3-kinase gene expression in skeletal muscle and adipose tissue of non-insulin-dependent diabetes mellitus patients. Diabetologia 42:358-364

90. Tremblay F, Lavigne C, Jacques H, Marette A (2001) Defective insulin-induced GLUT4 translocation in skeletal muscle of high fat-fed rats is associated with alterations in both Akt/protein kinase B and atypical protein kinase C (zeta/lambda) activities. Diabetes 50:1901-1910

91. Mauvais-Jarvis F, Ueki K, Fruman DA et al. (2002) Reduced expression of the murine p85alpha subunit of phosphoinositide 3-kinase improves insulin signaling and ameliorates diabetes. J Clin Invest 109:141-149

92. Terauchi Y, Tsuji Y, Satoh S et al. (1999) Increased insulin sensitivity and hypoglycaemia in mice lacking the p85 alpha subunit of phosphoinositide 3-kinase. Nat Genet 21:230-235

93. Carvalho E, Jansson PA, Nagaev I, Wenthzel AM, Smith U (2001) Insulin resistance with low cellular IRS-1 expression is also associated with low GLUT4 expression and impaired insulin-stimulated glucose transport. FASEB J 15:1101-1103

94. Miele C, Formisano P, Condorelli G et al. (1997) Abnormal glucose transport and GLUT1 cell-surface content in fibroblasts and skeletal muscle from NIDDM and obese subjects. Diabetologia 40:421-429

95. Zhande R, Mitchell JJ, Wu J, Sun XJ (2002) Molecular mechanism of insulin-induced degradation of insulin receptor substrate 1. Mol Cell Biol 22:1016-1026

96. Rui L, Fisher TL, Thomas J, White MF (2001) Regulation of insulin/insulin-like growth factor-1 signaling by proteasome-mediated degradation of insulin receptor substrate-2. J Biol Chem 276:40362-40367

97. Buren J, Liu HX, Lauritz J, Eriksson JW (2003) High glucose and insulin in combination cause insulin receptor substrate-1 and -2 depletion and protein kinase B desensitisation in primary cultured rat adipocytes: possible implications for insulin resistance in type 2 diabetes. Eur J Endocrinol 148:157-167

98. Pirola L, Bonnafous S, Johnston AM, Chaussade C, Portis F, Van Obberghen E (2003) Phosphoinositide 3-kinasemediated reduction of insulin receptor substrate-1/2 protein expression via different mechanisms contributes to the insulin-induced desensitization of its signaling pathways in L6 muscle cells. J Biol Chem 278:15641-15651

99. Paz K, Liu YF, Shorer H et al. (1999) Phosphorylation of insulin receptor substrate-1 (IRS-1) by protein kinase $\mathrm{B}$ positively regulates IRS-1 function. J Biol Chem 274:28816-28822

100. Esposito DL, Li Y, Vanni C et al. (2003) A novel T608R missense mutation in insulin receptor substrate-1 identified in a subject with type 2 diabetes impairs metabolic insulin signaling. J Clin Endocrinol Metab 88:1468-1475

101. Withers DJ, Gutierrez JS, Towery H et al. (1998) Disruption of IRS-2 causes type 2 diabetes in mice. Nature 391:900-904

102. Nolan JJ, Freidenberg G, Henry R, Reichart D, Olefsky JM (1994) Role of human skeletal muscle insulin receptor kinase in the in vivo insulin resistance of noninsulindependent diabetes mellitus and obesity. J Clin Endocrinol Metab 78:471-477

103. Maegawa H, Shigeta Y, Egawa K, Kobayashi M (1991) Impaired autophosphorylation of insulin receptors from abdominal skeletal muscles in nonobese subjects with NIDDM. Diabetes 40:815-819 
104. Krook A, Bjornholm M, Galuska D et al. (2000) Characterization of signal transduction and glucose transport in skeletal muscle from type 2 diabetic patients. Diabetes 49:284-292

105. Caro JF, Sinha MK, Raju SM et al. (1987) Insulin receptor kinase in human skeletal muscle from obese subjects with and without noninsulin dependent diabetes. J Clin Invest 79:1330-1337

106. Klein HH, Vestergaard H, Kotzke G, Pedersen O (1995) Elevation of serum insulin concentration during euglycemic hyperinsulinemic clamp studies leads to similar activation of insulin receptor kinase in skeletal muscle of subjects with and without NIDDM. Diabetes 44:1310 1317

107. Rice KM, Turnbow MA, Garner CW (1993) Insulin stimulates the degradation of IRS-1 in 3T3-L1 adipocytes. Biochem Biophys Res Commun 190:961-967

108. Carvalho E, Jansson PA, Axelsen M et al. (1999) Low cellular IRS 1 gene and protein expression predict insulin resistance and NIDDM. FASEB J 13:2173-2178

109. Rondinone CM, Wang LM, Lonnroth P, Wesslau C, Pierce JH, Smith U (1997) Insulin receptor substrate (IRS) 1 is reduced and IRS-2 is the main docking protein for phosphatidylinositol 3-kinase in adipocytes from subjects with non-insulin-dependent diabetes mellitus. Proc Natl Acad Sci USA 94:4171-4175

110. Shao J, Yamashita H, Qiao L, Friedman JE (2000) Decreased Akt kinase activity and insulin resistance in C57BL/KsJ-Leprdb/db mice. J Endocrinol 167:107115

111. Nawano M, Ueta K, Oku A et al. (1999) Hyperglycemia impairs the insulin signaling step between PI 3-kinase and Akt/PKB activations in ZDF rat liver. Biochem Biophys Res Commun 266:252-256

112. Oku A, Nawano M, Ueta K et al. (2001) Inhibitory effect of hyperglycemia on insulin-induced Akt/protein kinase $\mathrm{B}$ activation in skeletal muscle. Am J Physiol Endocrinol Metab 280:E816-E824

113. Yu C, Chen Y, Cline GW et al. (2002) Mechanism by which fatty acids inhibit insulin activation of insulin receptor substrate-1 (IRS-1)-associated phosphatidylinositol 3-kinase activity in muscle. J Biol Chem 277:50230-50236

114. Kim YB, Shulman GI, Kahn BB (2002) Fatty acid infusion selectively impairs insulin action on Akt1 and protein kinase $\mathrm{C}$ lambda/zeta but not on glycogen synthase kinase-3. J Biol Chem 277:32915-32922

115. Dresner A, Laurent D, Marcucci M et al. (1999) Effects of free fatty acids on glucose transport and IRS-1-associated phosphatidylinositol 3-kinase activity. J Clin Invest 103:253-259

116. Schlaepfer IR, Pulawa LK, Ferreira LD, James DE, Capell WH, Eckel RH (2003) Increased expression of the SNARE accessory protein Munc18c in lipid-mediated insulin resistance. J Lipid Res 44:1174-1181

117. Wrede CE, Dickson LM, Lingohr MK, Briaud I, Rhodes CJ (2003) Fatty acid and phorbol ester-mediated interference of mitogenic signaling via novel protein kinase $\mathrm{C}$ isoforms in pancreatic beta-cells (INS-1). J Mol Endocrinol 30:271-286

118. Sacks FM (2002) Dietary fat, the Mediterranean diet, and health: reports from scientific exchanges, 1998 and 2000. Introduction. Am J Med 113:1S-4S

119. Taouis M, Dagou C, Ster C, Durand G, Pinault M, Delarue J (2002) N-3 polyunsaturated fatty acids prevent the defect of insulin receptor signaling in muscle. Am J Physiol Endocrinol Metab 282:E664-E671
120. Grimble RF (2002) Inflammatory status and insulin resistance. Curr Opin Clin Nutr Metab Care 5:551-559

121. Spranger J, Kroke A, Mohlig M et al. (2003) Inflammatory cytokines and the risk to develop type 2 diabetes: results of the prospective population-based European Prospective Investigation into Cancer and Nutrition (EPIC)-Potsdam Study. Diabetes 52:812-817

122. Hotamisligil GS, Spiegelman BM (1994) Tumor necrosis factor alpha: a key component of the obesity-diabetes link. Diabetes 43:1271-1278

123. Hemi R, Paz K, Wertheim N, Karasik A, Zick Y, Kanety H (2002) Transactivation of ErbB2 and ErbB3 by tumor necrosis factor-alpha and anisomycin leads to impaired insulin signaling through serine/threonine phosphorylation of IRS proteins. J Biol Chem 277:8961-8969

124. Senn JJ, Klover PJ, Nowak IA, Mooney RA (2002) Interleukin-6 induces cellular insulin resistance in hepatocytes. Diabetes 51:3391-3399

125. Senn JJ, Klover PJ, Nowak IA et al. (2003) Suppressor of cytokine signaling-3 (SOCS-3), a potential mediator of interleukin-6-dependent insulin resistance in hepatocytes. J Biol Chem 278:13740-13746

126. Shanmugam N, Reddy MA, Guha M, Natarajan R (2003) High glucose-induced expression of proinflammatory cytokine and chemokine genes in monocytic cells. Diabetes 52:1256-1264

127. Exel E van, Gussekloo J, Craen AJ de et al. (2002) Low production capacity of interleukin-10 associates with the metabolic syndrome and type 2 diabetes: the Leiden 85-Plus Study. Diabetes 51:1088-1092

128. Singh R, Barden A, Mori T, Beilin L (2001) Advanced glycation end-products: a review. Diabetologia 44:129146

129. Abdel-Wahab YH, O'Harte FP, Ratcliff H, McClenaghan NH, Barnett CR, Flatt PR (1996) Glycation of insulin in the islets of Langerhans of normal and diabetic animals. Diabetes 45:1489-1496

130. Lindsay JR, McKillop AM, Mooney MH, O'Harte FP, Bell PM, Flatt PR (2003) Demonstration of increased concentrations of circulating glycated insulin in human Type 2 diabetes using a novel and specific radioimmunoassay. Diabetologia 46:475-478

131. Ruggiero-Lopez D, Rellier N, Lecomte M, Lagarde M, Wiernsperger N (1997) Growth modulation of retinal microvascular cells by early and advanced glycation products. Diabetes Res Clin Pract 34:135-142

132. Inagaki Y, Yamagishi S, Okamoto T, Takeuchi M, Amano S (2003) Pigment epithelium-derived factor prevents advanced glycation end products-induced monocyte chemoattractant protein-1 production in microvascular endothelial cells by suppressing intracellular reactive oxygen species generation. Diabetologia 46:284-287

133. Treins C, Giorgetti-Peraldi S, Murdaca J, Van Obberghen E (2001) Regulation of vascular endothelial growth factor expression by advanced glycation end products. J Biol Chem 276:43836-43841

134. Makita Z, Yanagisawa K, Kuwajima S et al. (1995) Advanced glycation endproducts and diabetic nephropathy. J Diabetes Complications 9:265-268

135. Miele C, Riboulet A, Maitan MA et al. (2003) Human glycated albumin affects glucose metabolism in L6 skeletal muscle cells by impairing insulin-induced insulin receptor substrate (IRS) signaling through a protein kinase $\mathrm{C}\{$ alpha $\}$-mediated mechanism. J Biol Chem 278:47376-47387

136. Rossetti L (2000) Perspective: hexosamines and nutrient sensing. Endocrinology 141:1922-1925 
137. Marshall S, Bacote V, Traxinger RR (1991) Discovery of a metabolic pathway mediating glucose-induced desensitization of the glucose transport system. Role of hexosamine biosynthesis in the induction of insulin resistance. J Biol Chem 266:4706-4712

138. Ciaraldi TP, Carter L, Nikoulina S, Mudaliar S, McClain DA, Henry RR (1999) Glucosamine regulation of glucose metabolism in cultured human skeletal muscle cells: divergent effects on glucose transport/phosphorylation and glycogen synthase in non-diabetic and type 2 diabetic subjects. Endocrinology 140:3971-3980

139. Chen H, Ing BL, Robinson KA, Feagin AC, Buse MG, Quon MJ (1997) Effects of overexpression of glutamine:fructose-6-phosphate amidotransferase (GFAT) and glucosamine treatment on translocation of GLUT4 in rat adipose cells. Mol Cell Endocrinol 135:67-77

140. Vosseller K, Wells L, Lane MD, Hart GW (2002) Elevated nucleocytoplasmic glycosylation by O-GlcNAc results in insulin resistance associated with defects in Akt activation in 3T3-L1 adipocytes. Proc Natl Acad Sci USA 99:5313-5318

141. Chen G, Liu P, Thurmond DC, Elmendorf JS (2003) Glucosamine-induced insulin resistance is coupled to O-linked glycosylation of Munc18c. FEBS Lett 534:5460

142. Parker GJ, Lund KC, Taylor RP, McClain DA (2003) Insulin resistance of glycogen synthase mediated by o-linked N-acetylglucosamine. J Biol Chem 278:1002210027
143. Veerababu G, Tang J, Hoffman RT et al. (2000) Overexpression of glutamine:fructose-6-phosphate amidotransferase in the liver of transgenic mice results in enhanced glycogen storage, hyperlipidemia, obesity, and impaired glucose tolerance. Diabetes 49:2070-2078

144. Cooksey RC, Hebert LF Jr, Zhu JH, Wofford P, Garvey WT, McClain DA (1999) Mechanism of hexosamine-induced insulin resistance in transgenic mice overexpressing glutamine:fructose-6-phosphate amidotransferase: decreased glucose transporter GLUT4 translocation and reversal by treatment with thiazolidinedione. Endocrinology $140: 1151-1157$

145. Pouwels MJ, Jacobs JR, Span PN, Lutterman JA, Smits P, Tack CJ (2001) Short-term glucosamine infusion does not affect insulin sensitivity in humans. J Clin Endocrinol Metab 86:2099-2103

146. Monauni T, Zenti MG, Cretti A et al. (2000) Effects of glucosamine infusion on insulin secretion and insulin action in humans. Diabetes 49:926-935

147. Kaneto H, Xu G, Song KH et al. (2001) Activation of the hexosamine pathway leads to deterioration of pancreatic beta-cell function through the induction of oxidative stress. J Biol Chem 276:31099-31104

148. Ramachandran C, Kennedy BP (2003) Protein tyrosine phosphatase 1B: a novel target for type 2 diabetes and obesity. Curr Top Med Chem 3:749-757

149. Asante-Appiah E, Kennedy BP (2003) Protein tyrosine phosphatases: the quest for negative regulators of insulin action. Am J Physiol Endocrinol Metab 284:E663-E670 